\title{
Effects of Respiratory Alkalosis on Thromboxane-Induced Pulmonary Hypertension in Piglets
}

\author{
G. J. REDDING, R. L. GIBSON, C. B. DAVIS, AND W. E. TRUOG \\ Division of Neonatal and Respiratory Diseases, Department of Pediatrics, University of Washington School of \\ Medicine, Seattle, Washington 98195
}

\begin{abstract}
Acute hypoxic pulmonary vasoconstriction is attenuated by respiratory alkalosis. It is unknown if alkalosis similarly reduces pulmonary vasoconstriction produced by thromboxane A2. Respiratory alkalosis does not always attenuate persistent pulmonary hypertension in newborns, some of whom have elevated serum thromboxane B2 levels. We hypothesized that alkalosis attenuates thromboxane-induced pulmonary vasoconstriction less than it does hypoxic pulmonary vasoconstriction in infants. Hemodynamic responses to respiratory alkalosis during pulmonary vasoconstriction produced in random order by breathing $12 \%$ inspired oxygen and by infusing $0.1 \mu \mathrm{g} / \mathrm{kg} /$ min of the thromboxane-mimetic $\mathbf{U} 46,619$ were compared in eight 2-wk-old piglets. Hypoxia increased mean pulmonary artery pressure from $12 \pm 3$ to $29 \pm 2 \mathrm{~mm} \mathrm{Hg}$ and pulmonary vascular resistance (PVR) from $11 \pm 4$ to $25 \pm$ $8 \mathrm{mmHg} / \mathrm{L} / \mathrm{min} ; \mathrm{U} 46,619$ increased pulmonary artery pressure from $16 \pm 5$ to $37 \pm 6 \mathrm{~mm} \mathrm{Hg}$ and PVR from $14 \pm 5$ to $51 \pm 17 \mathrm{~mm} \mathrm{Hg} / \mathrm{liter} / \mathrm{min}$. U46,619 also decreased cardiac output accounting in part for the greater increase in PVR compared to hypoxia-induced vasoconstriction. Respiratory alkalosis decreased PVR to $14 \pm 6 \mathrm{~mm} \mathrm{Hg} /$ liter/min during exposure to hypoxia and to $28 \pm 9 \mathrm{~mm}$ $\mathrm{Hg} / \mathrm{liter} / \mathrm{min}$ during infusion of $U 46,619$. In six additional piglets with $\mathrm{U} 46,619$-induced pulmonary vasoconstriction, the effects of lung stretch and hypocapnic alkalosis were separated by doubling tidal volume and then adding inspired $\mathrm{CO}_{2}$ to return $\mathrm{PaCO}_{2}$ to prehyperventilation levels. Respiratory alkalosis decreased PVR from $52 \pm 36$ to 35 $\pm 21 \mathrm{~mm} \mathrm{Hg} / \mathrm{liter} / \mathrm{min}$. Despite the increased tidal volume, PVR increased to $53 \pm 35 \mathrm{Hg} / \mathrm{liter} / \mathrm{min}$ when $\mathrm{PaCO}_{2}$ returned to $44 \pm 5 \mathrm{~mm} \mathrm{Hg}$. Respiratory alkalosis rather than lung stretch reduces thromboxane-induced and hypoxia-induced pulmonary vasoconstriction by equal proportions. (Pediatr Res 24: 558-562, 1988)
\end{abstract}

\section{Abbreviations}

$\mathrm{CO}$, cardiac output

HPV, hypoxic pulmonary vasoconstriction

Pcw, end-expiratory pulmonary capillary wedge pressure

Ppa, mean pulmonary artery pressure

PPHN, persistent pulmonary hypertension of the newborn Psa, mean systemic artery pressure

Received March 29, 1988; accepted June 29, 1988.

Correspondence Gregory J. Redding, M.D., Box RD-20, Division of Neonata and Respiratory Diseases, Department of Pediatrics, University of Washington School of Medicine, Seattle, WA 98195.

Supported in part by Grants NIH-HL19187, NIH-HL01205 (WET) MCH00095, and ALA Research Training Fellowship (R.L.G.)
PVR, pulmonary vascular resistance

SVR, systemic vascular resistance

HR, heart rate

Paw, peak proximal airway pressure

$\mathrm{PvO}_{2}$, mixed venous oxygen tension

Acute HPV in both adult and young animals is attenuated by respiratory and metabolic alkalosis (1-4). Although alveolar hypoxia is not necessarily the cause of idiopathic PPHN, clinicians hyperventilate infants with PPHN to produce respiratory alkalosis in an attempt to selectively reduce PVR, increase pulmonary blood flow, and improve arterial oxygenation by reducing rightto-left shunting of venous blood through the ductus arteriosus and foramen ovale $(5,6)$. Despite ventilation with $1.0 \mathrm{FIO}_{2}$ and hyperventilation, pulmonary hypertension does not fall below systemic levels in some of these infants, leading to a mortality of $17 \%$ or more (7-9). This experience has prompted a search for endogenous vasoactive substances which increase PVR in the absence of alveolar hypoxia, any of which may play a pathogenic role in some infants with PPHN. Hammerman, et al. (10) have reported increased serum levels of thromboxane B2, the stable metabolite of the pulmonary vasoconstrictor thromboxane A2, in some infants with PPHN. Stenmark et al. (11) have measured elevated levels of vasoconstrictor leukotrienes C4 and D4 in the bronchial washings of infants with PPHN. The effect of respiratory alkalosis on pulmonary hypertension produced by circulating endogenous vasoconstrictors is unknown. We hypothesized that respiratory alkalosis produced by hyperventilation would attenuate pulmonary vasoconstriction produced by a mimetic of thromboxane A2 less than hypoxia-induced pulmonary vasoconstriction in infants. We subsequently examined if increased tidal volume associated with respirator-induced hyperventilation reduced thromboxane-induced pulmonary hypertension independent of hypocapnic alkalosis.

\section{MATERIALS AND METHODS}

Animal preparation. Fourteen piglets, $16 \pm 5$ days and $3.5 \pm$ $0.4 \mathrm{~kg}$ (mean $\pm \mathrm{SD}$ ), were anesthetized with $45 \mathrm{mg} / \mathrm{kg}$ intravenous pentobarbital, heparinized, and mechanically ventilated via a tracheostomy tube at a tidal volume of $12 \pm 2 \mathrm{ml} / \mathrm{kg}$ and a rate which maintained $\mathrm{PaCO}_{2}$ of $40 \pm 3 \mathrm{~mm} \mathrm{Hg}$ at the onset of each experiment. Animals were initially paralyzed with $0.3 \mathrm{mg} /$ $\mathrm{kg}$ pancuronium bromide intravenously; anesthesia and paralysis were maintained for the duration of the experiment with hourly administration of $3 \mathrm{mg} / \mathrm{kg}$ of pentobarbital and $0.3 \mathrm{mg} / \mathrm{kg}$ pancuronium. Body temperature was monitored with a rectal 
probe (Yellow Springs Instrument Co., Yellow Springs, $\mathrm{OH}$ ) and maintained with heat lamps at a temperature of $38.5 \pm 0.5^{\circ} \mathrm{C}$. A no. 5 French thermodilution balloon-tipped catheter was placed in the left branch of the pulmonary artery using fluoroscopy. This catheter was used to continuously measure Ppa and intermittently measure $\mathrm{Pcw}, \mathrm{CO}$, and mixed venous blood gas tensions. A second catheter was placed in the ascending aorta via the internal carotid artery to continuously measure Psa and intermittently measure arterial blood gas tensions. A catheter was placed in the superior vena cava via an external jugular vein to infuse $U 46,619$. Tidal volume and respiratory frequency were measured from the tracheostomy tube with a pneumotachograph placed distal to a one-way valve on the expiratory side of the ventilator circuit (13). Paw was measured at the proximal tracheostomy port. Pressures were measured with Statham p23Db transducers and electrically averaged to obtain mean values using a Hewlet-Packard amplifier and chart recorder. Phasic aortic pressure recordings were used to count HR. CO by thermodilution was obtained by averaging three measurements using an Edwards 9520A cardiac output computer (American Edwards Laboratory, Irvine, $\mathrm{CA}$ ) under each experimental condition. Blood gas tensions, $\mathrm{pH}$, and inspired gas composition were determined using a Corning $168 \mathrm{pH}$ /blood gas analyzer (Corning Medical, Medfield, MA). PVR was calculated from the formula, $\mathrm{PVR}=\mathrm{Ppa}-\mathrm{Pcw} / \mathrm{CO} ; \mathrm{SVR}$ was estimated from the formula, $\mathrm{SVR}=\mathrm{Psa} / \mathrm{CO}$.

U46,619 preparation. The thromboxane mimetic, U46,619, which is 9,11,dideoxy-1 1a,9a epoxymethano-prostaglandin F2a (Upjohn Pharmaceutical Company, Kalamazoo, MI), was supplied as $1 \mathrm{mg} / \mathrm{ml}$ in methylacetate. Aliquots of $100 \mu \mathrm{g}$ were removed, dried, and resuspended in $95 \%$ ethanol and stored at $-20^{\circ} \mathrm{C}$. Before each experiment, an aliquot was removed, thawed, and combined in a variable amount of normal saline to a final ethanol concentration of $0.03-0.05 \%$. This solution was administered at $0.15 \mathrm{ml} / \mathrm{min}$ to deliver a dose of $0.075-0.15 \mu \mathrm{g} /$ $\mathrm{kg} / \mathrm{min}$.

\section{Experimental design}

Experiment 1: Comparison of Effects of Hyperventilation on Alveolar Hypoxia and U46,619-induced Pulmonary Vasoconstriction. Eight piglets were studied to determine the relative effect of respiratory alkalosis upon both hypoxic and U46,619induced pulmonary vasoconstriction. Initial hemodynamic measurements were made after ventilating animals with 0.26 $\mathrm{FIO}_{2}$ when hemodynamic indices had been stable for $15 \mathrm{~min}$. Animals then received either alveolar hypoxia or U46,619 first and, after recovery, received the alternative vasoconstrictive stimulus. The hypoxic challenge was created by ventilating animals with $0.12 \mathrm{FIO}_{2}$ and measuring hemodynamic and blood gas indices $20 \mathrm{~min}$ after the onset of hypoxia. Animals were then hyperventilated by increasing both tidal volume and ventilator rate for an additional $20 \mathrm{~min}$ of continued hypoxia before hemodynamic and blood gas measurements were repeated. During hyperventilation, the inspired oxygen concentration was adjusted to maintain the same end-tidal and therefore arterial oxygen tension that existed before hyperventilation. The alternative vasoconstrictive challenge included infusion of $0.075-$ $0.15 \mu \mathrm{g} / \mathrm{kg} / \mathrm{min}$ of $\mathrm{U} 46,619$ while the animals were ventilated with $0.26 \mathrm{FIO}_{2}$. Supplemental oxygen was used to avoid the confounding effects of hypoxic pulmonary vasoconstriction based upon preliminary experience that U46,619 in piglets breathing room air reduced $\mathrm{PaO}_{2}$ from $79 \pm 5$ to $62 \pm 6 \mathrm{~mm} \mathrm{Hg}$ $(n=4)$. The chosen dose of $\mathrm{U} 46,619$ doubled mean pulmonary artery pressure in the absence of hypoxic pulmonary vasoconstriction.

Hemodynamic and blood gas indices were measured $20 \mathrm{~min}$ after the onset of the infusion when $\mathrm{PaCO}_{2}$ was normal and 20 min after the onset of hyperventilation. A recovery period of 30 min occurred between challenges with vasoconstrictive stimuli and the second challenge was not initiated until hemodynamic measurements and blood gas tensions returned to prechallenge values. At the conclusion of the experiment, each animal was sacrificed with an overdose of pentobarbital.

Experiment 2: Effect of Lung Stretch and Respiratory Alkalosis on U46,619-induced Pulmonary Vasoconstriction. Six additional piglets of the same weight and postnatal age ventilated with 0.26 $\mathrm{FIO}_{2}$ were studied while receiving $0.1 \pm 0.03 \mu \mathrm{g} / \mathrm{kg} / \mathrm{min}$ of $\mathrm{U} 46,619$. The relative effects of increasing lung distension with increased tidal volume and of reducing $\mathrm{PaCO}_{2}$ were separated by adding $\mathrm{CO}_{2}$ to the inspired gas while doubling tidal volume. Piglets were randomized to receive either increased tidal volume followed $20 \mathrm{~min}$ later by addition of $\mathrm{CO}_{2}$ or alternatively increased tidal volume with increased inspired $\mathrm{CO}_{2}$ followed 20 min later by discontinuation of supplemental inspired $\mathrm{CO}_{2}$ and continued hyperventilation. Hemodynamic indices and blood gas tensions were measured before and $20 \mathrm{~min}$ after the onset of U46,619 administration during normal ventilation, $20 \mathrm{~min}$ after the onset of hyperventilation with or without supplemental $\mathrm{FiCO}_{2}$, and $40 \mathrm{~min}$ after the onset of hyperventilation with the alternative option of supplemental $\mathrm{CO}_{2}$ as described above. Supplemental $\mathrm{FiCO}_{2}(3.5 \pm 0.4 \%)$ was delivered in a quantity that returned $\mathrm{PaCO}_{2}$ to prehyperventilation values.

Data analysis. Hemodynamic and blood gas measurements were compared in the first experiment using a one-way analysis of variance (Minitab Release 82.1, Pennsylvania State University, 1984) and unpaired Student's $t$ tests using a Bonferroni correction factor to account for multiple comparisons (14) to discern significant differences between conditions before and after initiation of a vasoconstrictive stimulus and between conditions of vasoconstriction and subsequent respiratory alkalosis. The percent change in hemodynamic values in response to alkalosis during hypoxia and during infusion of U46,619 was compared using a paired Student's $t$ test. The one-way analysis of variance and unpaired Student's $t$ tests were also used to compare data measured among conditions of U46,619-induced vasoconstriction with and without hyperventilation with and without supplemental inspired $\mathrm{CO}_{2}$. A $p$ value of $<0.02$ was considered statistically significant.

\section{RESULTS}

Experiment 1. Hemodynamic and respiratory gas exchange values for eight piglets before and after respiratory alkalosis was superimposed upon hypoxic pulmonary vasoconstriction and upon U46,619-induced pulmonary vasoconstriction are presented in Table 1. Individual responses in $\mathrm{CO}$ and Ppa are illustrated in Figure 1 to demonstrate consistent responses of variable magnitude that occurred among animals with variable baseline values of Ppa, CO, and PVR.

By design, Ppa increased by a similar proportion, $237 \pm 46 \%$ versus $257 \pm 82 \%$, when vasoconstriction was produced by $12 \%$ inspired oxygen or by infusion of $0.1 \mu \mathrm{g} / \mathrm{kg} / \mathrm{min}$ of $\mathrm{U} 46,619$. This was accompanied by a variable change in cardiac output among animals exposed to hypoxia which did not significantly differ compared to the mean baseline normoxic values of the group (Fig. 1). In contrast, U46,619 consistently reduced cardiac output compared to preinfusion values in every animal. HR increased in every animal from $167 \pm 24$ to $209 \pm 44$ beats/min in response to hypoxia but did not change consistently (183 \pm 23 versus $179 \pm 19$ beats/min) during infusion of U46,619. Pulmonary capillary wedge pressure did not change significantly during the hypoxic exposure or infusion of U46,619. The net result was a statistically greater increase in PVR among animals during $U 46,619$ infusion $(395 \pm 180 \%)$ than during exposure to alveolar hypoxia $(229 \pm 74 \%)(p<0.05)$. During both conditions of pulmonary vasoconstriction, $\mathrm{PaCO}_{2}, \mathrm{pH}$, and SVR did not change. As expected, $\mathrm{PaO}_{2}$ fell significantly in response to alveolar hypoxia but not when animals were ventilated with $26 \% \mathrm{FIO}_{2}$ before and during the infusion of $\mathrm{U} 46,619 . \mathrm{PvO}_{2}$ fell as expected 


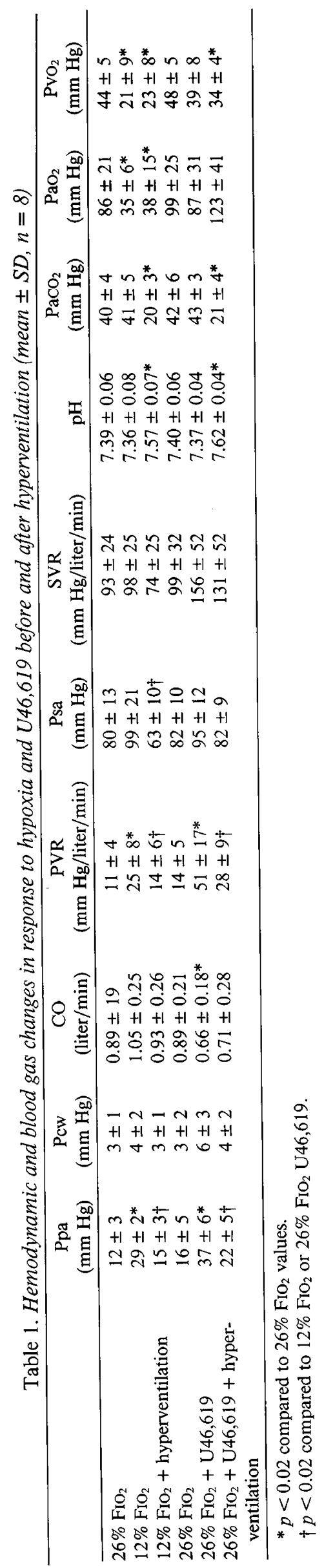

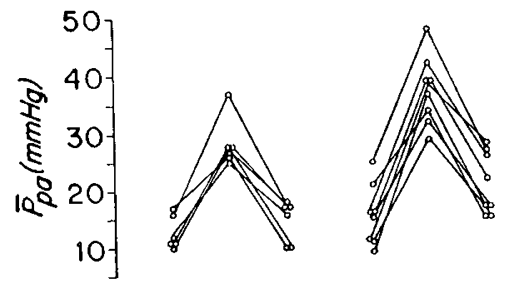
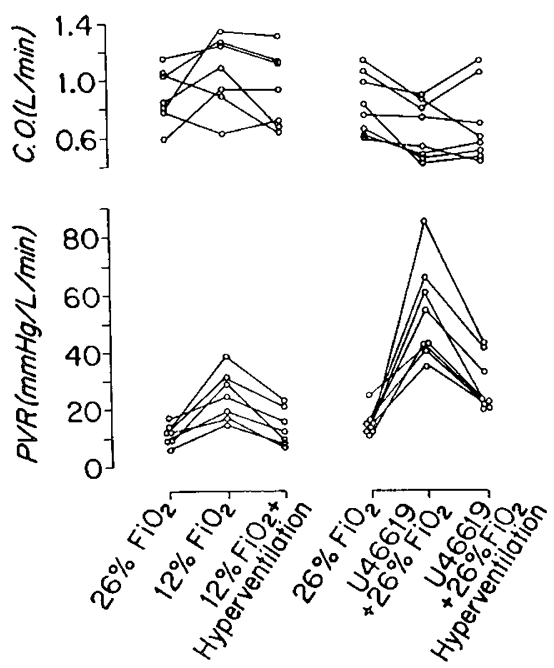

Fig. 1. Individual changes in Ppa, CO, and PVR in response to $12 \%$ $\mathrm{FiO}_{2}$ and $\mathrm{U} 46,619$ before and after superimposition of respiratory alkalosis. See Table 1 for statistical analysis of data for each experimental condition.

during exposure to $12 \% \mathrm{FrO}_{2}$ but also decreased significantly after the onset of U46,619 in association with the decreased CO.

Respiratory alkalosis during exposure to hypoxia and during infusion of U46,619 were produced by increasing both tidal volume and ventilator rate as depicted in Table 2 . The increase in minute ventilation and Paw were similar during the hypoxic exposure and infusion of U46,619. Consequently, increased minute ventilation reduced $\mathrm{PaCO}_{2}$ and increased arterial $\mathrm{pH}$ equally during both conditions of pulmonary vasoconstriction (Table 1). Respiratory alkalosis reduced Ppa by equal proportions (53 \pm $12 \%$ versus $60 \pm 10 \%$ ) compared to values measured during normocarbic vasoconstriction produced by hypoxia and U46,619. However, respiratory alkalosis did not return Ppa to preinfusion levels during administration of U46,619. Hyperventilation did not significantly influence cardiac output in animals receiving hypoxia or U46,619 (Fig. 1). More specifically, the decreased $\mathrm{CO}$ in response to U46,619 was not consistently improved by respiratory alkalosis despite a consistent increase HR from $179 \pm 19$ to $209 \pm 35$ beats/min and a reduction in Ppa (Fig. 1). Respiratory alkalosis reduced PVR by equal proportions $(54 \pm 14 \%$ versus $55 \pm 6 \%)$ under conditions of pulmonary vasoconstriction produced by hypoxia and U46,619 (Table 1).

Experiment 2. Table 3 displays the effects of U46,619 infusion before and after hypocapnic and normocarbic mechanical overventilation with twice the baseline minute volume. As in the first experiment, U46,619 increased pulmonary artery pressure and PVR significantly. During hyperventilation as depicted in Table 2, $\mathrm{PaCO}_{2}$ fell to $23 \pm 4 \mathrm{~mm} \mathrm{Hg}$, and $\mathrm{pH}$ rose to $7.61 \pm 0.06$ (Table 2). Lung stretch was reflected by the significant increase in tidal volume and Paw (Table 2). Paw, tidal volume, and minute volume did not change when $\mathrm{CO}_{2}$ was added to the inspired gas. Respiratory alkalosis associated with increased minute volume, as in experiment 1 , reduced Ppa to $64 \pm 11 \%$ and PVR to $63 \pm 9 \%$ of prehyperventilation values, respectively; $\mathrm{CO}$ did not change in response to hyperventilation. Respiratory alkalosis did not return Ppa or PVR to preinfusion values during 
Table 2. Indices of ventilation for experiment 1 and 2

\begin{tabular}{lcccc}
\hline & $\begin{array}{c}\text { Tidal volume } \\
(\mathrm{ml} / \mathrm{breath})\end{array}$ & $\begin{array}{c}\text { Ventilator rate } \\
\text { (breaths/min) }\end{array}$ & $\begin{array}{c}\text { Minute volume } \\
(\mathrm{L} / \mathrm{min})\end{array}$ & $\begin{array}{c}\text { Paw } \\
\left(\mathrm{cm} \mathrm{H} \mathrm{H}_{2} \mathrm{O}\right)\end{array}$ \\
\hline Experiment 1 $(n=8)$ & & & & \\
$\quad$ Baseline-hypoxic exposure & $41 \pm 5$ & $25 \pm 5$ & $1.04 \pm 0.26$ & $12 \pm 2$ \\
Hyperventilation-hypoxic exposure & $74 \pm 13^{*}$ & $32 \pm 8$ & $2.34 \pm 7^{*}$ & $22 \pm 5^{*}$ \\
Baseline-U46,619 infusion & $40 \pm 6$ & $25 \pm 5$ & $1.02 \pm 0.29$ & $12 \pm 2$ \\
Hyperventilation-U46,619 infusion & $77 \pm 13^{*}$ & $34 \pm 10$ & $2.5 \pm 0.77^{*}$ & $24 \pm 4^{*}$ \\
& & & & \\
Experiment 2 $(n=6)$ & $30 \pm 6$ & $23 \pm 3$ & $0.68 \pm 0.17$ & $11 \pm 1$ \\
Baseline-U46,619 Infusion & $54 \pm 7^{*}$ & $24 \pm 5$ & $1.3 \pm 0.31^{*}$ & $20 \pm 4^{*}$ \\
Overventilation-U46,619 & & & \\
\hline
\end{tabular}

$* p<0.02$, Student's $t$ tests.

Table 3. Effects of increased tidal volume versus hypocapnic alkalosis on U46,619-induced pulmonary hypertension (mean $\pm S D, n=6$ )

\begin{tabular}{|c|c|c|c|c|c|c|c|c|}
\hline & $\begin{array}{c}\mathrm{Ppa} \\
(\mathrm{mm} \mathrm{Hg})\end{array}$ & $\begin{array}{c}\text { Pcw } \\
(\mathrm{mm} \mathrm{Hg})\end{array}$ & $\begin{array}{c}\mathrm{CO} \\
\text { (liter/min) }\end{array}$ & $\begin{array}{c}\text { PVR } \\
(\mathrm{mm} \mathrm{Hg})\end{array}$ & $\begin{array}{c}\mathrm{PaO}_{2} \\
(\mathrm{~mm} \mathrm{Hg})\end{array}$ & $\begin{array}{c}\mathrm{PvO}_{2} \\
(\mathrm{~mm} \mathrm{Hg})\end{array}$ & $\begin{array}{c}\mathrm{PaCO}_{2} \\
(\mathrm{~mm} \mathrm{Hg})\end{array}$ & $\mathrm{pH}$ \\
\hline $26 \% \mathrm{FrO}_{2}$ & $13 \pm 2 *$ & $3 \pm 1$ & $0.83 \pm 0.24$ & $13 \pm 6^{*}$ & $108 \pm 10$ & $46 \pm 5$ & $42 \pm 4$ & $7.42 \pm 0.08$ \\
\hline $26 \% \mathrm{FIO}_{2}+\mathrm{U} 46619$ & $31 \pm 4$ & $4 \pm 3$ & $0.70 \pm 0.33$ & $52 \pm 36$ & $111 \pm 11$ & $42 \pm 7$ & $43 \pm 3$ & $7.40 \pm 0.08$ \\
\hline $\begin{array}{c}26 \% \mathrm{FIO}_{2}+\mathrm{U} 46619+ \\
\mathrm{V}_{\mathrm{E}}+0 \% \mathrm{FIO}_{2}\end{array}$ & $20 \pm 5^{*}$ & $4 \pm 2$ & $0.60 \pm 0.22$ & $32 \pm 21^{*}$ & $144 \pm 10^{*}$ & $34 \pm 2^{*}$ & $23 \pm 4^{*}$ & $7.61 \pm 0.06^{*}$ \\
\hline $\begin{array}{c}26 \% \mathrm{FIO}_{2}+\mathrm{U} 46619+ \\
\uparrow \mathrm{V}_{\mathrm{E}}+4 \% \mathrm{FICO}_{2}\end{array}$ & $30 \pm 5$ & $5 \pm 1$ & $0.59 \pm 0.26$ & $53 \pm 35$ & $121 \pm 19$ & $36 \pm 6$ & $44 \pm 5$ & $7.39 \pm 0.06$ \\
\hline
\end{tabular}

$* p<0.02$ compared to $26 \% \mathrm{FiO}_{2}+\mathrm{U} 46619$ values.

administration of $U 46,619$. Ventilation with twice the minute volume containing supplemental $\mathrm{CO}_{2}$ returned $\mathrm{PaCO}_{2}, \mathrm{pH}, \mathrm{Ppa}$, and PVR to prehyperventilation normocarbic levels during infusion of $U 46,619$.

\section{DISCUSSION}

The results of this study demonstrate that respiratory alkalosis produced by doubling minute ventilation reduces pulmonary vasoconstriction produced by alveolar hypoxia and intravenous U46,619 by equal proportions in young piglets. However, in contrast to the effects of alkalosis on HPV, the reduction in Ppa and PVR during infusion with U46,619 does not return these indices to preinfusion values. Furthermore, the reduction in PVR during infusion of U46,619 occurs in response to respiratory alkalosis rather than lung stretch per se. These results suggest that pulmonary hypertension produced by elevated thromboxane synthesis in young animals and perhaps human newborns with otherwise normal pulmonary vascular anatomy should be only partially attenuated by respiratory alkalosis.

In contrast to changes in pulmonary artery pressure, respiratory alkalosis did not alter the reduction in $\mathrm{CO}$ produced by the thromboxane mimetic U46,619. Presuming the distribution of $\mathrm{CO}$ and metabolic rate remained unchanged, the decreased $\mathrm{PvO}_{2}$ during infusion of U46,619 suggests a small but significant increase in oxygen extraction in response to decreased peripheral perfusion despite respiratory alkalosis. Barbiturate anesthesia may have contributed to the reduction in CO during the U46,619 infusion, but recovery of $\mathrm{CO}$ to preinfusion levels $30 \mathrm{~min}$ after discontinuation of U46,619 suggests that this potential drug interaction was not sustained. U46,619 reduced CO but did not change HR, suggesting that the drug primarily reduced stroke volume. The results are consistent with previous work suggesting that thromboxane A2 produced coronary vasospasm independent of pulmonary vasoconstriction which may adversely affect cardiac performance $(15,16)$.

Alternative pharmacologic interventions to treat thromboxane-induced pulmonary hypertension in infants have been described using the piglet model of group B streptococcal sepsis. In seven previous reports, intravenous group B streptococci produced a common hemodynamic response which included an increase in Ppa of $260-350 \%$ of baseline values, a reduction in $\mathrm{CO}$ by $30-60 \%$, and an increase in PVR of $420-775 \%(17-23)$. Each of these reports has investigated a pharmacologic intervention that might improve hemodynamic function in septic infant animals. Intravenous epinephrine, indomethacin, dazmegrel, and the leukotriene receptor antagonist FPL57231 have been administered, and all reduce the degree of elevated PVR by both reducing $\mathrm{Ppa}$ and improving $\mathrm{CO}$. The cyclooxygenase inhibitor, indomethacin, and the thromboxane synthetase inhibitor, dazmegrel, completely reversed the elevation in Ppa (17, 21-23). Epinephrine and FPL57231 reduced Ppa by only 20 and 35\%, respectively $(21,22)$. All of these agents improved $\mathrm{CO}$ during sepsis but did so to a variable degree. However, in all studies, CO never returned to normal despite treatment.

U46,619 infusion in this study produced the same hemodynamic changes that occur during low dose group B streptococcal infusion in piglets. A dose of U46,619 was administered that would double Ppa without producing systemic hypotension or metabolic acidosis in order to avoid these confounding events. Respiratory alkalosis reversed elevated Ppa more effectively than epinephrine or FPL57231 but less effectively than indomethacin or dazmegrel. Respiratory alkalosis was as ineffective as epinephrine and much less effective than FPL57231, dazmegrel, or indomethacin in improving the thromboxane-induced reduction in cardiac output. These findings suggest that hemodynamic abnormalities associated with increased thromboxane A2 production may be better treated with specific inhibitors of thromboxane synthetase rather than hyperventilation or catecholamine therapy.

Clinical diseases, such as group B streptococcal sepsis and some forms of persistent pulmonary hypertension of the newborn in the absence of sepsis, are associated with elevated levels of serum thromboxane B2 levels (10). Both entities are associated with right-to-left shunting of mixed venous blood through the patent ductus and/or the foramen ovale, producing profound hypoxemia unresponsive to assisted ventilation with $100 \%$ oxygen (6). Although hyperventilation therapy to produce respiratory alkalosis has proven an effective therapy for pulmonary hypertension in most of these patients, not all children improve $(7,8)$.

Our results may in part explain this experience. Although 
hyperventilation attenuated the effects of U46,619, PVR remained twice the value measured before infusion of the drug, suggesting incomplete reversal of thromboxane-induced pulmonary vasoconstriction (Tables 1 and 2 ). If pulmonary vasoconstriction in infants with some forms of PPHN does indeed result form increased synthesis of thromboxane $\mathrm{A} 2$, then respiratory alkalosis should reduce PVR relative to SVR and reduce rightto-left shunting through the patent ductus arteriosus. However, shunting of venous blood through the foramen ovale will result when right atrial pressure is greater than left atrial pressure. Right atrial pressure is determined in part by right ventricular enddiastolic pressure which in turn is determined by both right ventricular compliance and right ventricular afterload (24). The persistent reduction in $\mathrm{CO}$ and calculated stroke volume during infusion of U46,619 despite additional hyperventilation in young piglets, suggests that right ventricular compliance may have been primarily reduced by the thromboxane mimetic independent of PVR. In the newborn with a patent foramen ovale and elevated thromboxane production, right-to-left shunting of blood through the foramen due to increased right atrial pressures and to abnormal right ventricular compliance characteristics would not be necessarily influenced by respiratory alkalosis. Two-wk-old piglets do not have foramenal right-to-left shunting during hypoxia and U46,619 infusions based upon dye dilution $\mathrm{CO}$ curve profiles. Furthermore, right atrial pressure was not measured in this study. Studies evaluating pulmonary hemodynamics and right heart function in younger animals, i.e. newborns with patent foramen ovales, during states of elevated thromboxane synthesis are warranted to corroborate this speculation and more closely relate experimental findings to clinical management of human neonates.

The results demonstrate that pulmonary vasoconstriction due to stimuli other than hypoxia is partially attenuated by respiratory alkalosis. Nonetheless, clinical entities associated with pulmonary hypertension and elevated serum levels of thromboxane may be accompanied by abnormal cardiac function which might be more consistently improved with therapeutic modalities other than respiratory alkalosis.

\section{REFERENCES}

1. Shapiro BJ, Simmons DH, Linde LM 1966 Pulmonary hemodynamics during acute acid-base changes in the intact dog. Am J Physiol 21:1026-1032

2. Malik AB, Kidd BSL 1973 Independent effects of changes in $\mathrm{H}^{+}$and $\mathrm{CO}_{2}$ concentrations on hypoxic pulmonary vasoconstriction. J Appl Physiol $34: 318-323$

3. Schreiber MD, Heymann MA, Soifer SJ 1986 Increased arterial pH, not decreased $\mathrm{PaCO}_{2}$, attenuates hypoxia-induced pulmonary vasoconstriction in newborn lambs. Pediatr Res 20:113-117
4. Lyrene RK, Welch KA, Guillermo G, Philips JB III 1985 Alkalosis attenuates hypoxic pulmonary vasoconstriction in neonatal lambs. Pediatr Res 19:1268-1271

5. Peckham GJ, Fox WW 1978 Physiologic factors effecting pulmonary artery pressure in infants with persistent pulmonary hypertension. $J$ Pediatr 93:1005-1010

6. Drummond WH, Gregory GA, Heymann MA, Phibbs RA 1981 The independent effects of hyperventilation, tolazoline, and dopamine on infants with persistent pulmonary hypertension. J Pediatr 98:603-611

7. Ferrara B, Johnsho DE, Chang PN, Thompson TR 1984 Efficacy and neurologic outcome of profound hypocapneic alkalosis for the treatment of persistent pulmonary hypertension in infancy. J Pediatr 105:457-461

8. Ballard RA, Leonard CH 1984 Developmental follow-up of infant with persistent pulmonary hypertension of the newborn. Perinatal Clin North Am 11:737-744

9. Shankaran S, Farooki ZL, Desai R 1982 Beta-hymolytic streptococcal infection appearing as persistent foetal circulation. Am J Dis Child 136:725

10. Hammerman C, Lass N, Strates E, Komar K, Chi Bui K 1987 Prostanoids in neonates with persistent pulmonary hypertension. J Pediatr 110:470-472

11. Stenmark KR, James SL, Voelkel NF, Toews WH, Reeves JT, Murphy RC 1983 Leukotriene $C_{4}$ and $D_{4}$ in neonates with hypoxemia and pulmonary hypertension. N Engl J Med 309:77-80

12. Bundy GL 1975 The synthesis of prostaglandin endoperoxide analogs. Tetrahedron Lett 24:1957-1960

13. Truog WE, Standaert TA 1978 Nonrebreathing valve for spontaneously breathing or mechanically ventilated animals. J Appl Physiol 44:974-976

14. Zar JH 1984 Biostatistical Analysis, 2nd ed. Prentice-Hall, Inc., Engelwood Cliffs, NJ

15. Ellis EF, Oelz O, Roberts LJ, Payne NA, Sweetman BJ, Nies AS, Oates JA 1976 Coronary arterial smooth muscle contraction by a substance released by platelets: evidence that it is thromboxane. Science 193:1135-1137

16. Fitzgerald DJ, Doran J, Jackson E, FitzGerald GA 1986 Coronary vascular occlusion mediated via Thromboxane $\mathrm{A}_{2}$-endoperoxide receptor activation in vivo. $\mathrm{J}$ Clin Invest 77:496-502

17. Runkle B, Goldberg RN, Streitfeld MM, Clark MR, Buron E, Setzer ES, Bancalari E 1984 Cardiovascular changes in group B streptococcal sepsis in the piglet: response to indomethacin and relationship to prostacyclin and thromboxane $\mathrm{A}_{2}$. Pediatr Res 18:874-878

18. Sorensen GK, Redding GJ, Truog WE 1985 Mechanisms of pulmonary gas exchange abnormalities during experimental group B streptococcal infusion. Pediatr Res 19:922-926

19. Meadow WL, Rudinsky BF, Strates E 1986 Selective elevation of systemic blood pressure by epinephrine during sepsis-induced pulmonary hypertension in piglets. Pediatr Res 20:872-875

20. Goldberg RN, Suguihara C, Streitfeld MM, Bancalari A, Clark MR, Bancalari E 1986 Effects of a leukotriene antagonist on the early hemodynamic manifestations of group B streptococcal sepsis in piglets. Pediatr Res 20:1004-1008

21. Tarpey MN, Graybar GB, Lyrene RK, Godoy G, Oliver J, Gray BM, Philips JB, III 1987 Thromboxane synthesis inhibition reverses group B streptococcus-induced pulmonary hypertension. Crit Care Med 15:664-647

22. Truog WE, Gibson RL, Juul SE, Henderson WR, Redding GJ 1988 Neonatal group $B$ streptococcal sepsis: effects of late treatment with dazmegrel. Pediatr Res 23:352-356

23. Gibson RL, Truog WE, Redding GJ 1988 Thromboxane-associated pulmonary hypertension during three types of gram-positive bacteremia in piglets. Pediatr Res 23:553-556

24. Cabal LA, Devaskar U, Siassi B, Hodgman JE, Emmanouilides G 1980 Cardiogenic shock associated with perinatal asphyxia in preterm infants. J Pediatr 96:705-710 